\title{
Nutritional impact on muscle glycogen metabolism in lambs selected for muscling
}

\author{
K.M. Martin ${ }^{1,3}$, G.E Gardner ${ }^{1}$, J.M. Thompson ${ }^{1}$ and D.L. Hopkins ${ }^{2}$ \\ Australian Sheep Industry Cooperative Research Centre, \\ ${ }^{1}$ School of Rural Sciences and Natural Resources, University of New England \\ Armidale, NSW Australia 2351 \\ ${ }^{2}$ New South Wales Agriculture, Centre for Sheep Meat Development \\ Cowra, NSW Australia 2794
}

\begin{abstract}
Lambs from sires selected for high or low Estimated Breeding Values (EBVs) for yearling eye muscle development, were maintained on high or low energy rations. During the feeding period, they were exposed to a one-off bout of exercise designed to deplete muscle glycogen. The progeny of high muscling EBV sires had increased pre-exercise muscle glycogen concentration and post exercise rates of glycogen repletion; however this was only evidenced when Metabolizable Energy (ME) intakes were adequate. Generally ME intake increased rate of muscle glycogen repletion.
\end{abstract}

KEY WORDS: sheep, muscling, nutrition, exercise, glycogen

\section{INTRODUCTION}

Low pre-slaughter muscle glycogen levels are detrimental to meat quality, causing higher ultimate $\mathrm{pH}$ of meat, and darker colour (Gardner et al., 2001).

There has been a recent trend in the Australian sheep industry for selection of sires based on objective performance traits. These characteristics such as muscling, growth and fattening are rated using EBVs determined from progeny performance data. There is evidence in cattle breeds (Wegner et al., 2000), that selection for muscling increases the expression of type IIB fibres. Skeletal muscle consists of several different fibre types, broadly categorised as type I (slow oxidative), type IIA (fast oxidative), and type IIB (fast glycolytic), thus selection for muscling is likely to increase the glycolytic capacity of the muscle.

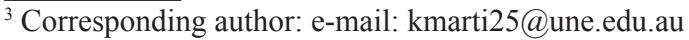


Fibre types also differ between muscles. Work in sheep has shown that the $M$. semitendinosus (ST) consists largely of type IIb fibres, and thus is associated with low levels of glycogen, low rates of glycogen resynthesis and a high susceptibility to stress induced glycogen depletion, making it a sensitive indicator of stress. The $M$. semimembranosus (SM) is a more sensitive indicator of glycogen repletion following stress, with a high proportion of type IIa fibres, correlating with high levels of glycogen, high rates of glycogen resynthesis and a low susceptibility to stress induced glycogen depletion (Picard et al., 2002).

Exercise can be used as a method for the controlled depletion of glycogen from muscle, allowing subsequent rates of glycogen repletion to be measured. In this study the effect of selection for muscling on muscle glycogen metabolism following exercise was studied in the SM and ST of lambs maintained on either roughage or concentrate rations.

\section{MATERIAL AND METHODS}

An experimental flock was produced of progeny from Merino ewes crossed with 17 Merino or Poll Dorset sires selected for either high or low EBVs for yearling eye muscle development. Each sire was represented by 6 to 8 mixed sex lambs.

At 10 weeks of age the lambs were weaned into individual pens, and randomly allocated within sire to either a low energy diet of a 50/50 lucerne and oaten chaff mix (ME $8.25 \mathrm{MJ} / \mathrm{kg}$ and $\mathrm{CP} 12.7 \%$ ) or a high energy diet of $55 \%$ barley, $25 \%$ lupins, $20 \%$ chaff (ME $11.65 \mathrm{MJ} / \mathrm{kg}$ and CP $16.64 \%$ ). The high energy treatment lambs were gradually adjusted to the ration over 4 weeks, with the full ration available for two weeks prior to and after the exercise challenge. Daily feed intakes and weekly liveweights were recorded.

At 12 weeks of age, and an average liveweight of $22.5 \pm 4.3 \mathrm{~kg}$, an exercise challenge was imposed consisting of $4 \times 15 \mathrm{~min}$ intervals at $8 \mathrm{~km} / \mathrm{h}$ (approx. $70 \%$ $\mathrm{VO}_{2}$ max, i.e. steady trot), with 15 min rest between intervals. Muscle biopsies (Gardner et al., 2001) were taken from the SM and ST prior to and immediately after exercise to determine basal glycogen concentration, and the level of depletion, and further biopsies were taken at $36 \mathrm{~h}$ and $72 \mathrm{~h}$ to determine rates of glycogen repletion. Muscle glycogen concentration represented the sum of glycogen, lactate and free glucose, as determined in (Gardner et al., 2001).

Linear mixed effects models $\left(\mathrm{SAS}^{\circledR}\right)$ were used to examine the effect of EBVs for eye muscle depth, yearling weight and fat score potential, muscle type (SM or ST), ME intake and liveweight, and interactions between these terms, on preexercise muscle glycogen concentration, exercise depletion and rate of glycogen repletion $72 \mathrm{~h}$ post exercise. Animal nested within sire, and sire nested within sire breed (Poll Dorset or Merino) were used as random effects. Non-significant terms $(\mathrm{P}>0.05)$ were sequentially deleted from the models. 


\section{RESULTS}

Higher levels of ME intake increased basal muscle glycogen concentration (Figure1) to a greater extent in the SM than the ST $(\mathrm{P}<0.05)$.

The highest sire muscling EBV almost doubled basal muscle glycogen concentrations (compared to the lowest), but only when ME intakes were at their highest level. It had no effect when ME intakes were low $(\mathrm{P}<0.05$; Figure 2). Following exercise muscle glycogen was depleted by about 55 and $85 \%$ in the SM and ST, respectively, and ME intakes generally were 35\% lower. Muscle

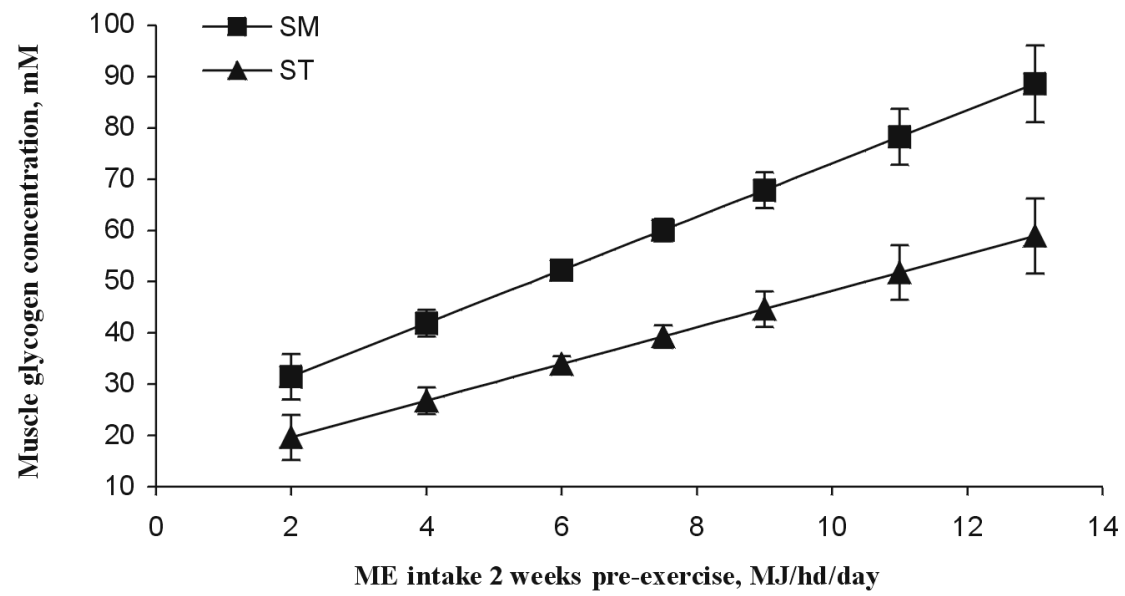

Figure 1. The effect of metabolizable energy intake on pre-exercise muscle glycogen concentration

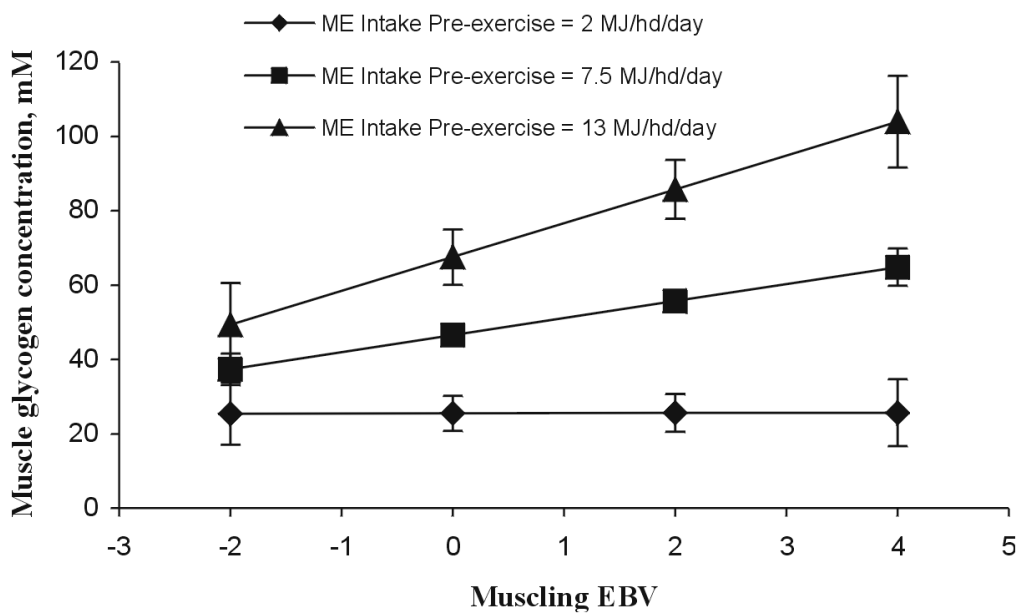

Figure 2. Effect of muscling EBV on muscle glycogen concentration at three levels of ME intake 


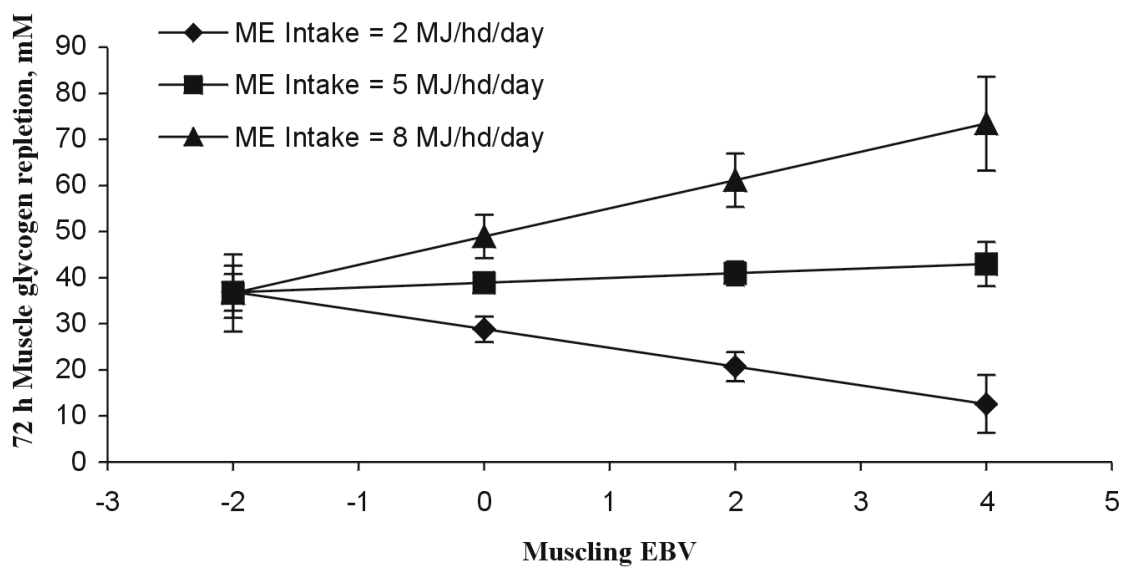

Figure $\underline{3} 4$. Effect of muscling EBV on $72 \mathrm{~h}$ muscle glycogen repletion at three levels of ME intake

glycogen repletion $72 \mathrm{~h}$ post exercise was generally improved by increasing ME intake $(\mathrm{P}<0.05$; Figure 3$)$. However, sire muscling EBV interacted with this response $(\mathrm{P}<0.05)$, increasing glycogen repletion when $\mathrm{ME}$ intakes were high (i.e. $8 \mathrm{MJ} /$ day), and decreasing it when ME intakes were low (i.e. $2 \mathrm{MJ} /$ day). Glycogen repletion at $72 \mathrm{~h}$ was also higher in the SM $(38 \pm 1.8 \mathrm{mM})$ than the ST $(28 \pm 2.0$ $\mathrm{mM} ; \mathrm{P}<0.05)$.

\section{DISCUSSION}

Sires selected for high muscling EBVs will produce progeny with raised muscle glycogen concentration, and faster rates of glycogen repletion post stress, potentially reducing the incidence of dark cutting. This response will only occur given adequate nutrition. The higher basal muscle glycogen concentration, and faster rates of post exercise glycogen repletion in the SM, supports the assertion that more oxidative muscle types are less prone to dark cutting.

\section{REFERENCES}

Gardner G.E., McIntyre B.L., Tudor G., Pethick D.W., 2001. The impact of nutrition on bovine muscle glycogen metabolism following exercise. Aust. J. Ag. Res. 52, 46, 461-470

Picard B., Lefaucheur L., Berri C., Duclos M.J., 2002. Muscle fibre ontogenesis in farm animal species. Reprod. Nutr. Develop. 42, 415-431

Wegner J., Albrecht E., Fiedler I., Teuscher F., Papstein H.-J., Ender K., 2000. Growth-and breedrelated changes of muscle fiber characteristics in cattle. J. Anim. Sci. 78, 1485-1496 